\title{
An Ontology-Based E-Learning Framework for Healthcare Human Resource Management*
}

\author{
Lidia BĂJENARU ${ }^{1}$, Ion SMEUREANU ${ }^{2}$, Alexandru BALOG ${ }^{1}$ \\ ${ }^{1}$ National Institute for Research \& Development in Informatics, \\ 8-10, Mareşal Averescu, Avenue, Bucharest, 011455, Romania \\ lidia.bajenaru@ici.ro, alexb@ici.ro. \\ ${ }^{2}$ Department of Economic Informatics and Cybernetics, \\ Bucharest University of Economic Studies, \\ 6 Romana Square, Bucharest, 010374, Romania \\ smeureanu@ase.ro.
}

\begin{abstract}
Human resources management is an essential prerequisite to enhance performance in healthcare organizations. Improving human resources management in a university hospital, first and foremost depends on how professional and knowledgeable the management team is, as well as on the competences and skills of its members. This paper describes a highly personalized e-learning system, which is able to take into account the individual's profile, learning style, initial knowledge and education needs. The system is based on new technologies: Semantic Web and ontologies. On these technologies are based the development of the constituent parts of the system: the student model, the model of the field of interest namely Healthcare Human Resources Management (HHRM) in Romania. The main benefit of the proposed elearning method consists in personalized training of managers. The characteristic feature of the suggested method largely lies in the fact that specific ontologies of the field of interest are implemented with the Protégé environment which relies on a personalized methodology. The paper presents the constituent parts and architecture of the proposed ontology-based e-learning system and a framework for its implementation in a real life platform. Even though the current system is tailored to the needs of HHRM , its application could be extended to other fields of knowledge and learning contexts.
\end{abstract}

Keywords: E-learning, personalization, ontology-based model, semantic web, human resource management, LMS.

\section{Introduction}

E-learning is currently a widely-spread technology in teaching establishments and beyond [29]. E-learning is also an alternative to continuing education in today's world as an information society or tomorrow's world as a knowledge society.

The great diversity of the users of e-learning systems requires new pedagogical approaches as well as an increased technological quality. In many works it is suggested that the success of e-learning resides in the quality of information technology, and use of modern technology in education must be supported $[5,18]$.

The Web 2.0 technology has been widely applied to e-learning systems in order to improve social communication and the transfer of knowledge to the virtual learning media

\footnotetext{
* This paper is based on two previous presentations in: "Journal of Economic Computation and Economic Cybernetics Studies and Research" and "The 14th International Conference on Informatics in Economy"(see references 3 and 4). This work presents new data from our research about the evaluation of the system ontology, and implementation of the developed solution.
}

[26]. Semantic Web technologies, respectively the ontologies, have been applied to e-learning systems development.

Some e-learning systems were primarily focused on the innovation process enabling students to generate new ideas and pass on knowledge [20] while other systems combined intelligent agents with an open e-learning platform with a view to providing a personalized teaching-learning process [1].

Personalization is an innovative approach into e-learning systems, representing an advanced stage in the development of learning systems. The students have different profiles according to studies, training, skills, concerns, their learning styles, objectives, preferences. All these lead to differences in individual training effectiveness through learning systems.

Health Human Resources are among the most important and expensive resources in this sector, and Human Resources Management (HRM) is regarded as a crucial element for the success of healthcare organizations [21]. Healthcare services are influenced by the diversity of patient and employee profiles, and also by the effect of technologies and economy globalization. 
An increased focus on responsibility and teamwork in healthcare services provisioning are important changes with a significant impact on the quality of services provided to the patient. Advances in HRM as well as examples of training solutions with the help of Web technologies are dwelt upon in different papers [28].

The aim of HHRM is to ensure the right number of healthcare human resources with adequate knowledge, aptitudes, attitudes and qualifications, able to fulfil the right tasks in the right place and at the right time with a view to attain the public healthcare objectives [4].

This paper presents a personalized e-learning system based on the technology of semantic Web meant to answer the training needs of human resources managers in a university hospital. Among other things, managers need to have their knowledge checked and updated by adding notions required by their professional position, in keeping with their profile, learning style and expectations.

The objectives of this system are: personalized learning, adapted educational content, reuse of the educational resources and interoperability for e-learning systems, as well as human resources management systems. Founded on these bases, the system aims to solve a series of current limitations of e-learning.

Within the proposed system, learning personalization takes into account the knowledge level, learning style (in keeping with the Felder-Silverman model), the aim of learning, the student's competences as well as his assessment and feedback. It will be achieved through innovative solutions in three fields: modelling the learning process, modelling the student, modelling the digital content.

The design of the learning process relies on the IMS (Information Management System) standards, which provide a conceptual framework for all three aspects. Modelling is achieved with the help of ontologies implemented with the Protégé environment, by using a methodology that suits the field and the student type.

This paper is organized as follows. Section 2 briefly presents the theoretical background. Section 3 presents the overview of system. Section 4 presents logical and technical architecture description, and implementation solution. Section 5 summarizes the main conclusions.

\section{Theoretical Background}

\subsection{E-learning in HHRM}

Recent studies [30] show that in Romania there is a need for professional training, and suggest the development of professional training adapted to the needs of the professionals working in the field of quality management in health care facilities at the highest quality standards acknowledged at European level.

The need for training is assessed in terms of knowledge and skills required to implement, audit and maintain the standard of high quality management in the health system.

Healthcare management has a high degree of complexity and it is in a process of continuous transformation, being a subject of interest for the managers in the healthcare units and related institutions, but also a high priority on the political agenda of many countries.

By providing an e-learning training program using Internet technologies, a continuous adaption to this form of education to the real needs of Romanian and European healthcare system is achieved. It also allows the acquirement of the specialized knowledge in an operational system to ensure professional competence in this field. Using this training, elearning is intended to help all those involved in the health system, to deepen knowledge in public health management services health and human resources management.

In our country, such programs are relatively new in health management, appearing in programs of postgraduate training and continuing professional development training courses organized by companies developing software and training within university programs (POSDRU).

The National School of Public Health, Management and Professional Development in Bucharest, which is actively involved in the achievement of strategies and policies for reform, initiated and conduct training courses to increase the effectiveness and efficiency of health services in the country.

There are many preoccupations for e-learning in health care sector worldwide. There are numerous e-learning platforms for knowledge in HRM and in HHRM. Medical Education Organizations supporting e-learning are also active. 
Many studies [27] certify the concern for elearning in health, towards using Internet technologies to enhance knowledge and performance in the field. E-learning technologies offer control over the educational content, allowing the students to reach their personal learning goals. In various contexts of medical education, e-learning appears to be at least as effective as traditional instructor-led modalities. Research in this field [23] highlights interests in training solutions using Web technologies in HRM domain.

\subsection{Semantic Web}

Innovations in e-learning, respectively new technologies such as Semantic Web provide a revolution in education, leading to individualized learning (adaptive), encouraging collaborative learning.

Semantic Web [6] may be exploited as a suitable platform for the deployment of elearning, as it provides all the means for the necessary learning process. Among its advantages for e-learning, providing Internet learning materials, which are connected by ontology, may be highlighted. This enables the student to adapt the training program through semantic queries about what he wants to receive in a personalized way. This allows the identification of the content according to his needs and goals.

Ontologies are widely used to represent common knowledge from heterogeneous sources, thus addressing the problem of interoperability.

Other studies [31] focus on the improvement of the quality and efficiency of e-learning systems using ontology in the development of personalized learning model. An adaptive learning environment is able to monitor its students' activities, interpret them, extrapolate the students' needs and preferences and decide on what knowledge is further needed.

Personalization, as an attribute of adaptive learning systems, consists in adjustment of educational materials according to personal features: student's learning styles and objectives. Creating an adaptive learning system that meets the students 'requirements, is a challenge, not only because students have different needs, but because they have different learning characteristics [7, 19].

Based on the research carried on by Fathi Essalmi et al. [9] there are several personalization parameters used in e-learning systems, among which:

- The student's level of knowledge;

- Preferences regarding media resources, particularly the form of the learning materials: text, images, films, audio, video;

- The Kolb learning cycle which defines an experiential learning model;

- The Honey-Mumford learning style which identified four learning styles based on Kolb experience;

- The Felder-Silverman learning style which identified five learning dimensions.

The learning environment based on learning styles has a positive influence in terms of students' achievements. Adapting learning to each one's style makes learning more efficient.

Tools that support ontology development process have been created. The most used methodologies for developing ontologies are METHOD 101 [22] and METHONDOLOGY [12]. These methodologies are basically used in this project.

Among the most relevant languages to describe ontologies are: Resource Description Framework (RDF), Web Ontology Language (OWL) and eXtensible Markup Language (XML). (OWL) [2] is a language for semantically enriched knowledge representation and complex representations of things, groups of things and relationships among things.

Tools for the building and formalization of the ontologies have also been created. Protégé instrument [25] is one of these. Protégé is an ontology editor based on Java; it is a standalone application, open source, with an extensible architecture.

\section{Overview of the System}

The proposed personalized e-learning system for the management team of a university hospital is a response to the need to improve the performance, competences and assessment skills of managers through an automatized method of information search in a particular field.

The implemented personalized concept is based on ontologies, and it provides new solutions to several aspects such as: profile, knowledge, learning style, learning objective, training level, 
student' competences, training level assessment and feedback.

This proposed e-learning system is based on the modelling of its components: the student's profile, the field of interest, the learning process [4]. The prototype system is based on the standards of the existing systems (SCORM, IEEE and IMS).

Some studies [24] have analysed the way in which ontologies can contribute to the student's modelling. Among the advantages of ontologybased modelling there are: formal semantics, reutilization, availability of efficient design tools.

\subsection{Student model}

Modelling the student's profile is one of the key factors influencing the automatized coaching systems in terms of training decisions. The student's profile ontology is an important feature to achieve the proposed personalization system [4].

In the proposed prototype, the student model is developed incrementally by the system using the data collected from the student and from the student-system interaction. The first source is a static one, while the second is dynamic.

The dynamic modelling of the student's profile tries to identify the student's characteristics through collecting information during the learning process. The student performance, along with information about the knowledge, are acquired during the training process. They are stored in the student's portfolio, serving to continuously update the student model in a dynamic way. The student model has been defined taking into account several aspects such as: previous knowledge in the field of interest (HHRM), learning style, learning objective, IMS standard recommendations.

The learning style is one of the most important parameters when it comes to differences among individuals, while also creating adaptive learning environments. The learning style refers to the different ways in which individuals understand information. The learning environments based on learning styles have a positive influence in terms of students' achievements [10].

Several learning style models have been developed, five of which have been given attention by the specialized literature. Among these there are Jung's Theory (Jung's Theory of
Psychological Type), and the models of learning style identification by Kolb [17], Felder and Silverman [10], Herrmann [14] and Dunn and Dunn [8].

There are numberless studies that focus on learning from the point of view of students' styles [32], pointing to the differences in terms of learning styles among students and how they influence their performance.

The members of the target group are characterized by various learning styles, with preferences for various types of information and a tendency to operate with information perceived in a different way. Some students learn better with visual presentations, others prefer verbal explanations, and some prefer active learning, while others are rather introspective [11].

In order to meet the individual needs of each student for an efficient training, the proposed elearning system puts forward personalized learning objects (materials) according to the learning style of each one. The Felder and Silverman model is at the basis of the learning style implemented in the proposed system.

For the implementation of the ontology of the student's profile, Protégé 4.3 has been chosen.

\subsection{Domain model}

In the development of the proposed system ontology, the objectives and the purpose have initially been identified, as follows: e-learning system components, fields of interest (HHRM), knowledge in this domain, according to students' preferences [4].

The modeling of the field of interest consists of decomposing body of available knowledge in a set of elements called concepts that are basic pieces of knowledge or information. A domain concept can be represented through one or several learning objects (LOs). LOs based on the IMS standard are a key-concept within this project; they are the basic building blocks allowing personalizing the content of the learning materials provided to a student.

The representation of the ontology followed several stages in accordance with the Methontology [12] methodology. Thus, the conceptualization and implementation stages are preceded by the stage in which concepts relevant for the field of interest but also for the suggested learning process are acquired. 
The concepts the student must learn, were identified in the acquisition phase (according Methondology) and have been represented in ontology editor Protégé, through classes, subclasses, properties, organized into a hierarchy. The relationships between ontology components are established. Relations indicate interactions among domain concepts. They define properties and attributes that characterize the domain classes. Inference rules extend the initially defined ontology.

The graphic representation of the identified concepts of the system ontology, as well as of the relationships among them are presented in Figure 1.

Examples of object properties are: "Person has competence Competence", which connects the Person class to Competence class, "Person has job Job ", which connects Job class to Person class. Relationships between concepts (synonymy, equivalence) have been identified and a hierarchy of properties has been created, these properties were linked with relevant concepts.

Also, axioms have been used to define the meaning of the components of ontology, to refine the concept and the relations among them. Thus, these complex relationships have been defined and allowed to get new information.

$\mathrm{FaCT}++[15]$ was used as a tool of reasoning, to assess the overall coherence of ontology, to provide new information or to validate / reject an initial assumption. This tool has also been used to check the consistency of the ontology.
Practical example in the personal application showing on new information obtained using axioms and $\mathrm{FaCT}++$ can be seen in Figure 2.

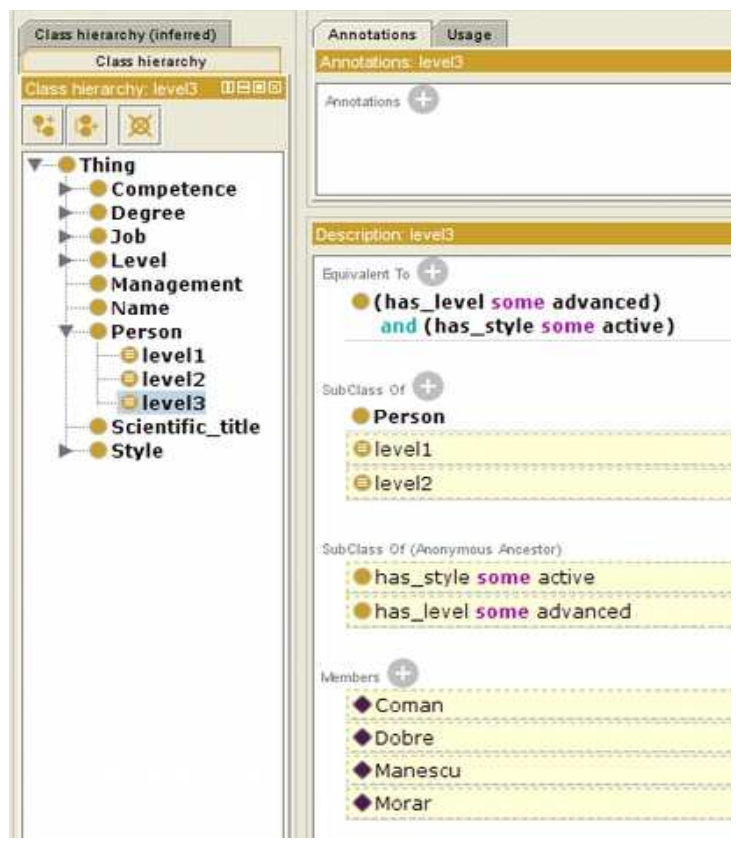

Figure 2. Practical example on new information

The domain ontology aims the following requirements:

- to describe the basic concepts used in relation to the competencies identified in human resources management by hospital managers;

- to enable query data stored in the knowledge base;

- to be able to match the right person for the position of manager.

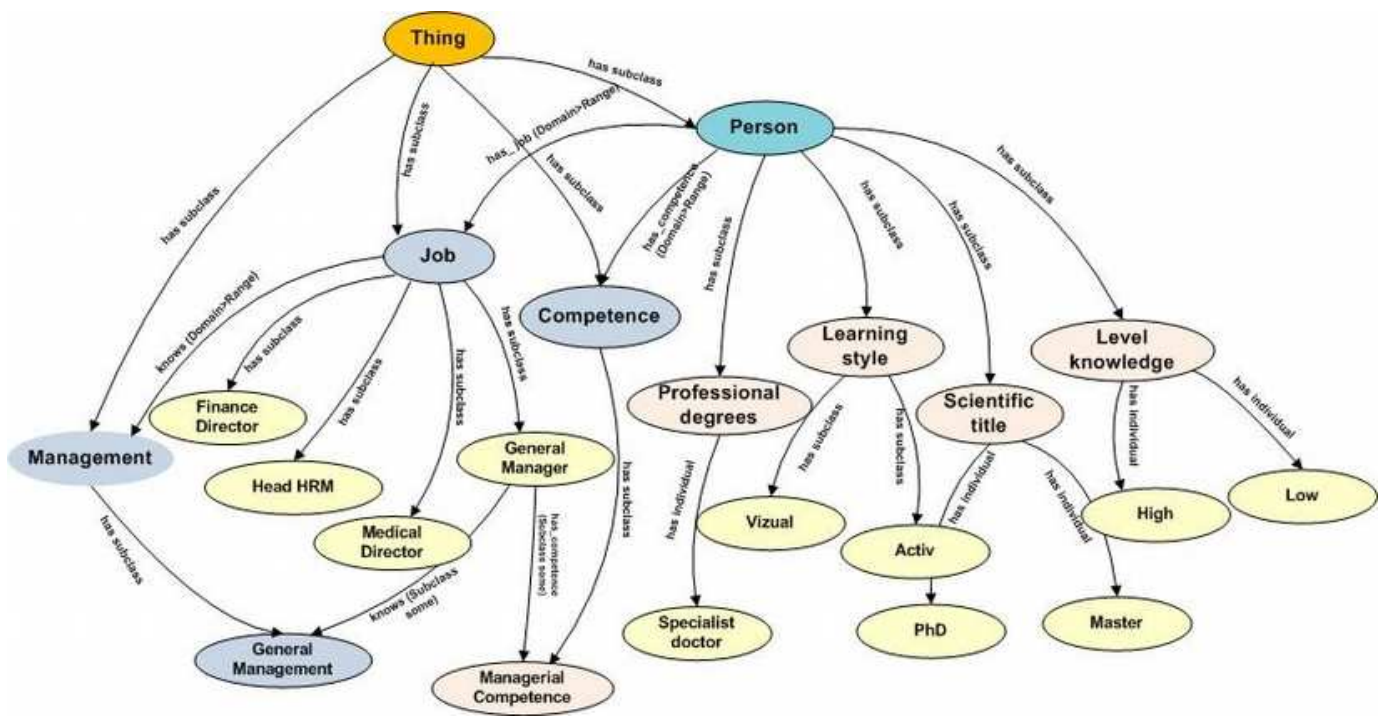

Figure 1. The concepts of the system ontology and the relationships among them obtained using axioms and $\mathrm{FaCT}++$ 


\subsection{Modelling learning}

The modelling of the learning process supposes the assessment of several variants in terms of personalization of the content and of the services provided to the student. This leads to the creation of a best complex scenario in several steps:

- Stipulation of personal training options (the whole course, a module, acquiring certain competences), personal data (such as education/qualifications, field of work) personal preferences (learning style, preassessment of the student's knowledge level);

- Pre-assessment of the student's knowledge level in accordance to his options;

- Personalization of the learning unit (course, lesson, module) depending on the student's options, knowledge level, profile and preferences, filling up the learning unit with computer-aided course specifics, final assessment and course end.

The scenario for the learning path suggested by the system is based on the student's knowledge level, learning style and needs. It should allow students the access to a particular knowledge field (e.g. a particular job), which is necessary in order to acquire the requested specific training. The personalization of the learning units is achieved through the selection of a LO for each concept specific to the learning field.

The system compares individual answers to questions (benchmarking testing) as against the knowledge needed in the field, and at the end of the process the student is given feedback and suggestions for additional training.

\section{The System Architecture}

The modelling of the training domain specific for Human Resources Management in a hospital and the use of ontologies in the building of personalized learning experience will be implemented in an intelligent learning Web platform.

Once the student has chosen the target concept of HRM, the system triggers the training process by evaluating several alternatives for the designing of an adequate course meant to meet both the student's current knowledge level and his learning style [4].
The core of the e-learning intelligent system is an ontology that plays the role of a systematic and comprehensive knowledge storage regarding the competences of the target group, containing basic concepts such as competence, management, person, skills, which allows applying the available knowledge and also their relationships with other concepts, instances and properties.

By using its own mechanisms, the system will establish a link between the target concepts selected by the student with the knowledge database of the HRM and with the student's current knowledge level, learning style, profile and preferences, and will provide the learning units (course, lesson, module) needed by his training.

The personalization of the learning units is achieved through the selection of a learning subject for each concept, based on the algorithm of the learning path [4].

In this way, a personalized learning program based on a specific ontology will be obtained as well as bibliographies adapted to the students' needs according to their profile and responsibilities of each member of the management team.

\subsection{The logical architecture}

The logical architecture integrates: (a) the Web server, which ensures the interface with the students; (b) the application programs, which performs the main functions of the system; (c) the database server, which stores the system's database (educational content, students' profiles and portfolios) [3].

The proposed system offers the following functionalities:

4.1.1 Management of the education content provides the content creation and editing, loading structure (initial load owl).

Before allowing students to register and access the system, it is necessary to complete the initialization process and the management of the education content. This process will be achieved by the administrator.

4.1.2. Building up and personalizing the learning unit, provides pre-assessment, registration of the student, creation of the student's profile, creation of a learning unit suitable for this.

Initialization is the process which allows the student accesses to the system for the first time. 
In this process, the unit student allocation occurs, so that an adequate personalized training content may be obtained.

4.1.3 Management of the learning unit, provides delivery of education objects, testing, communication, reporting.

After the initialization process has been done, the student is provided with the personalized training content on the basis of the model suggested by the system and elements characteristic of the student, such as the level (automatically established upon initialization), the student's particular learning style.

The flow relevant for this process is summarized in the following sequence diagram (Figure 3) and is presented below:

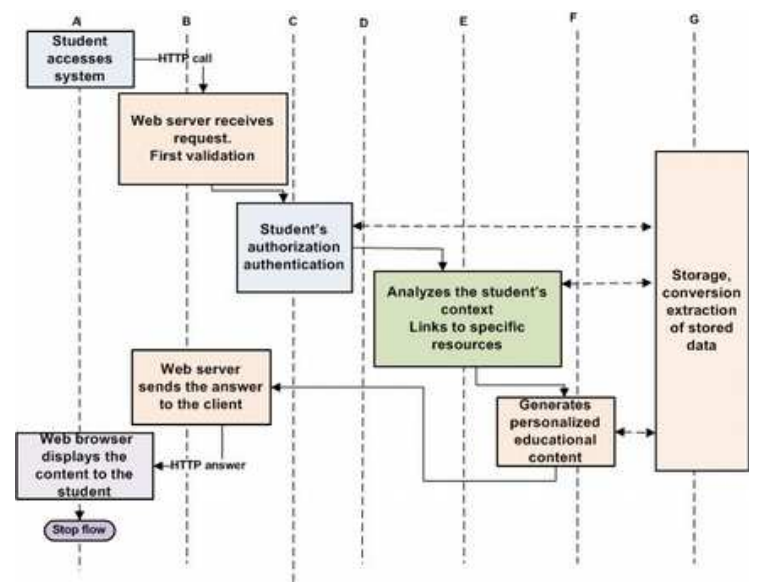

Figure 3. Flow process of accessing system

- The student accesses the system using a Web browser;

- The Web server receives the student's request. A first validation takes place, then the flow is directed towards other essential components of the system;

- The internal processing takes place (authorization and authentication of the student before he accesses resources);

- The analysis of the student context (profile and OWL information) takes place at the level of the Semantic Web component, and optimal connections among specific resources are achieved, adapted to the student's level and style. Previously, the student's training level has been set;

- At the level of the Content Generation component, the training material (learning object) is established, personalized so that it may suit the student's profile;
- The web server formats the answer and sends it to the student;

- The web browser displays the student's content;

- Stop flow.

4.1.4 Site administration, ensures registration and administration by the administrator

The administrator will be able to manage the system also by using the web interface (browser), where he will access a particular section of operational management.

\subsection{The technical architecture}

The architecture of the proposed Web-based intelligent training system is a client-server architecture on three layers. The client side manages the interface with the users, and their connection to the server. The personalized elearning system combines the student model with the domain model in order to provide education content adequate to the student's needs. The system adapts the course content to the results of the students' assessment tests.

The technical architecture consists of two main blocks: the client (Web browser) and the server. Additionally, at the server level there is the database server, which has the role to ensure the data in the system [3].

The proposed system is able to support the elearning activity in an interactive mode, based on the semantic web. The architecture diagram is presented in Figure 4. The components of this system are presented below:

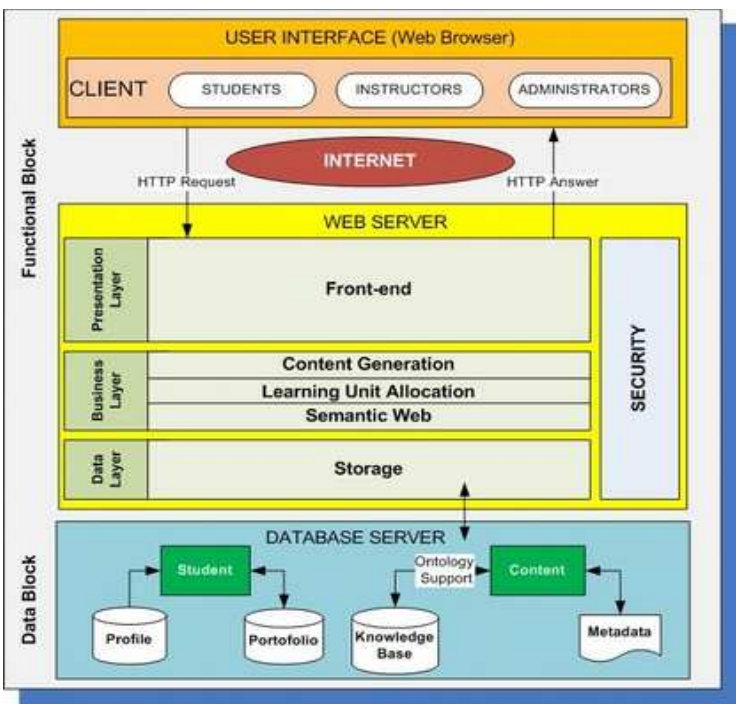

Figure 4. The System technical architecture diagram

A. User Interface ensures the user requests (URL) and then selects the working option; 
B. Front-end receives the student's requests, forwards them for internal processing and then sends an answer to the student;

C. Security is responsible with the authentication/validation of the students;

D. Learning Unit Allocation with the Semantic Web engine (E) analyse the specific context for each student already in the log-in stage, and identify the best personalized training mode;

E. Semantic Web is developed in a personalized way around a web/OWL semantic engine;

F. Content Generation generates personalized education content for each student;

G. Storage Component keeps student's profile.

\subsection{Implementation solution}

A Learning Management Systems (LMS) framework is used to implement the proposed system architecture.

LMS, also called Virtual Learning Environments (VLE) [33], is a web-based application, which automates the management, tracking and reporting of learning events. LMS provides a wide range of functions such as content authoring, course building, online examination, student evaluation, grade book, and collaborative learning.
The LMS makes it possible to give feedback regarding exams and homework, to organize the learning material, to store recordings about students, teaching staff and system, to issue reports [13].

LMS offers the student: personalized access to learning resources, learning management tools, self-assessment, and online support.

The LMS framework put forward in this paper tackles several important design aspects by means of a modular design approach.

The integrated modular architecture of the proposed e-learning system may be seen in Figure 5. The large modules are presented in the following:

- Content Store makes it possible to store the content on a backup hard disk and allows synchronization.

- Content Management and Integration Module (CMIM) are responsible for content management functions such as creation (authoring).

- User Management Module (UMM) manages the system front-office, such as registration and authentication. UMM manages the users and validates permission to access the system resources through the

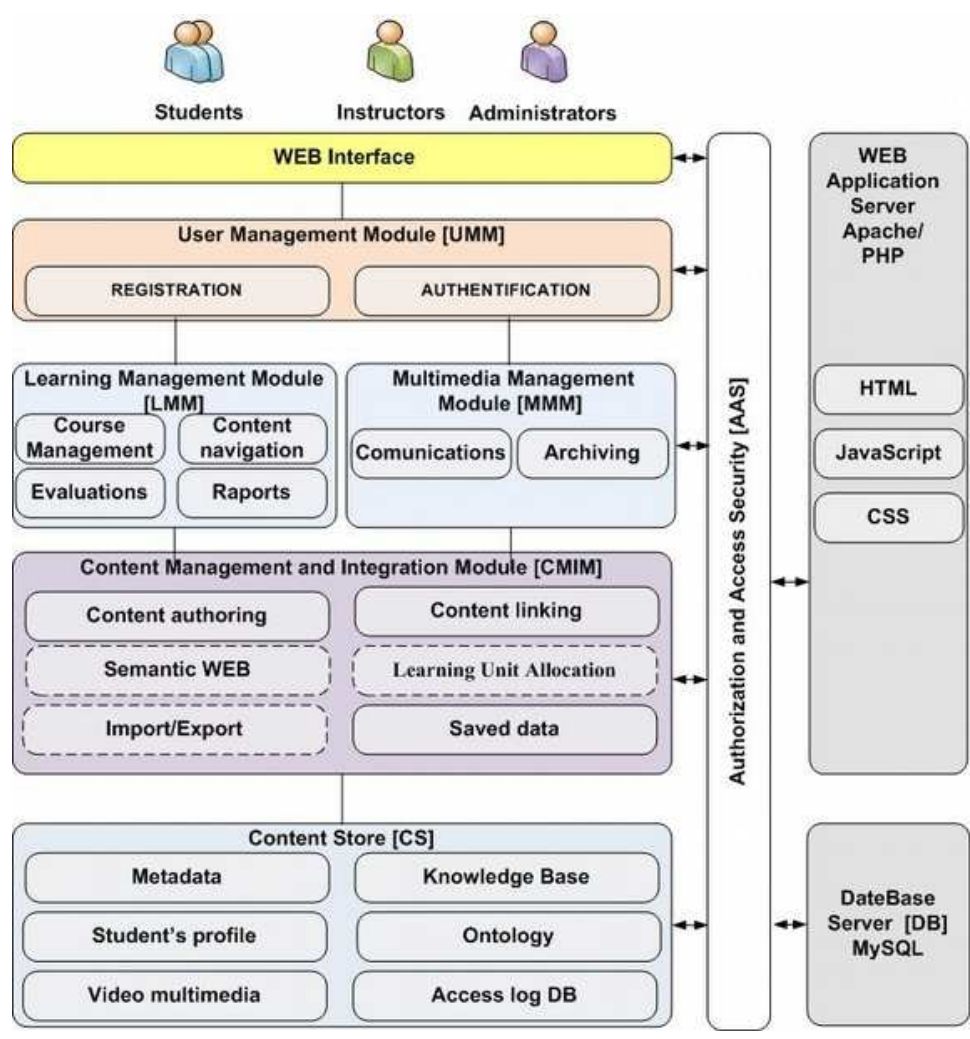

Figure 5. The ontology-based modular architecture of the system 
Learning Management Module (LMM) and Multimedia Management Module (MMM) functional modules.

Among the most popular LMS, Dokeos [16] was chosen to implement the e-learning process presented above. Dokeos is an open-source software developed by a Belgian company, Dokeos SPRL 2014. It is a modular objectoriented dynamic environment that can be personalized to suit learning requirements with new modules, respectively, with owl sequences.

\section{Conclusion}

In this paper a personalized e-learning system addressed to managers in a university hospital is proposed. This is based on Semantic Web and ontologies, technologies which allow the modelling of the constituent parts of the system: the student model, the domain model (HHRM), the learning path. The advantages of ontology-based modelling are: formal semantics, reutilization, availability of efficient design tool.

The advantage of this proposed e-learning method is personalized training of managers. In order to meet the individual needs of each student for an efficient training, the proposed elearning system puts forward personalized learning objects according to the learning style of each one. A characteristic feature of the suggested method is that the specific ontologies of the field of interest are implemented with the Protégé environment which relies on a personalized methodology.

The paper also presents the architecture of the proposed system and a framework for its implementation in a real life platform.

\section{REFERENCES}

1. ALEXANDRU, A., E. TÎRZIU, E. TUDORA, O. BICA, Enhanced Education by Using Intelligent Agents in Multi-Agent Adaptive e-learning Systems, Studies in Informatics and Control, vol. 24, no.1, 2015, pp. 13-22.

2. ALLEMANG, D., J. HENDLER, Semantic Web for the Working Ontologist. Modeling in RDF, RDFS, and OWL, Journal of Knowledge Management, vol. 6 , no. 1,2002 , pp. 40-51.
3. BĂJENARU, L., I. A. MARINESCU, I. SMEUREANU, A Framework for Designing an Ontology-Based ELearning System in Healthcare Human Resource Management, Proceeding of the 14-th International Conference on Informatics in Economy (IE2015), 2015, pg. 176-181.

4. BĂJENARU, L., I. SMEUREANU, An Ontology Based Approach for Modeling E-Learning in Healthcare Human Resource Management, Economic Computation and Economic Cybernetics Studies and Research (ECECSR), vol. 49, no. 1,2015 , pg. 23-40.

5. BALOG, A., Acceptance of e-Learning Systems: a Serial Multiple Mediation Analysis, Studies in Informatics and Control, vol. 24, no.1, 2015, pp. 101-110.

6. BERNERS-LEE, T., Weaving the Web: The Original Design and Ultimate Destiny of the World Wide Web by Its Inventor, HarperCollins Publishers, 1999.

7. CAKULAA, S., M. SEDLENIECEA, Development of a Personalized elearning Model Using Methods of Ontology, Procedia Computer Science, vol. 26, 2013, pp. 113-120.

8. DUNN, N., J. S. BEAUDRY, A. KLAVAS, Survey of Research on Learning Styles, Educational Leadership, vol. 46, no. 6, 1989, pp. 50-58.

9. ESSALMI, F., L. J. B. AYED, M. JEMNI, KINSHUK, S. GRAF., A Fully Personalization Strategy of E-learning Scenarios, Computers in Human Behavior, vol. 26, 2010, pp. 581-591.

10. FELDER, R. M., L. K. SILVERMAN, Learning and Teaching Styles in Engineering Education, Engineering Education, vol. 78(7), 1988, pp. 674-681.

11. FELDER, R. M., R. BRENT, Understanding Student Differences, Journal of Engineering Education, vol. 94, no. 1,2005 , pp. 57-72.

12. FERNÁNDEZ-LÓPEZ, M., A. GÓMEZPÉREZ, N. JURISTO, Methondology: From Ontological Art Towards Ontological Engineering, AAAI Symposium on Ontological Engineering, Stanford, 1997, pp. 33-40. 
13. GIGURUWA, N., D. H. ANH, D. PISHVA, A Multimedia Integrated Framework for Learning Management Systems, eLearning - Theories, Design, Software and Applications, Ritsumeikan Asia Pacific Univ., Japan, InTech, 2012, pp. 153-172.

14. HERRMANN, N., The Creative Brain, Lake Lure, N.C.: Brain Books, 1990.

15. http://owl.cs.manchester.ac.uk/tools/fact/.

16. http://www.dokeos.com.

17. KOLB, D. A., Experiential Learning: Experience as the Source of Learning and Development, Prentice-Hall, 1984.

18. KURILOVAS, E., A. JUSKEVICIENE, Creation of Web 2.0 Tools Ontology to Improve Learning, Computers in Human Behavior, vol 51, 2015, pp. 1380-1386.

19. LO, J. J., Y. C. CHAN, S. W. YEH, Designing an Adaptive Web-based Learning System based on Students' Cognitive Styles Identified Online, Comp. \& Ed., vol. 58, 2012, pp. 209-222.

20. NICULESCU, A., G. THORSTEINSSON, Enabling Idea Generation through Computer-Assisted Collaborative Learning, Studies in Informatics and Control, vol. 20, no.4, 2011, pp. 403-410.

21. NILES, N. J., Basic concepts of Health Care Human Resource Management, Jones \& Bartlett Publishers, 2013.

22. NOY, N., D. L. MCGUINESS, Ontology Development 101: A Guide to Creating Your First Ontology, Stanford Knowledge Systems Laboratory Technical Report KSL-01-05, 2001.

23. ONGENAE, F., M. ClAEYS, T. DUPONT, W. KERCKHOVE, P. VERHOEVE, T. DHAENE, F. TURCK, A Probabilistic Ontology-based Platform for Self-learning Context-aware Healthcare Applications, Expert Systems with Applications 40, 2013, pp. 7629-7646.

24. PRAMITASARI, L., A. N. HIDAYANTO, S. AMINAH, A. A. KRISNADHI, L. M. A. RAMADHANIE, Development of Student Model Ontology for Personalization in an e-Learning System based on Semantic Web, Proceedings of the International Conference on Advanced
Computer Science and Information Systems, 2009, pp. 434-439.

25. .Protégé, http://protege.stanford.edu/.

26. ROLLETT, H., M. LUX, M. STROHMAIER, G. DOSINGER, The Web 2.0 Way of Learning with Technologies, International Journal of Learning Technology, vol. 3, no. 1, 2007, pp. 87-107.

27. RUIZ, J. G., M. J. MINTZER, R. M. LEIPZIG, The Impact of e-Learning in Medical Education, Academic Medicine, vol. 81, no. 3, 2006, pp. 207-212.

28. SINGH, G., K. S. NEGI, Human Resource Management Practices in Large Hospitals of Dehradun, Uttarakhand, Global Journal of Management and Business Studies, vol. 3, no. 5,2013 , pp. 555-560.

29. SMEUREANU, I., N. ISĂILĂ, New Information Technologies for an Innovative Education, World Journal on Educational Technology, vol. 3, no.3, 2011, pp. 177-189.

30. Studiu de Evaluare a Nevoii de Formare a Managerilor Sistemelor Calității în Spitalele din România, proiect: LLP-LdVToI-2012/RO/019, 2012, http://www.crestcenter.org/pdf/Studiu evaluare nevoi de formare.pdf.

31. TRAUSAN-MATU, S., D. MARASCHI, S. CERRI, Ontology-Centered Personalized Presentation of Knowledge Extracted from the Web, Computer Science, nr. 2363, 2002, pp. 259-269.

32. VALASKI, J., A. MALUCELLI, S. REINEHR, Recommending Learning Materials According to Ontology-based Learning Styles, ICITA, Australia, 2011.

33. WELLER, M., Virtual Learning Environments: Using, Choosing and Developing Your VLE, Routledge, London, 2007. 